\title{
Scaled-Down Moderator Circulation Test Facility at Korea Atomic Energy Research Institute
}

\author{
Hyoung Tae Kim and Bo Wook Rhee \\ Korea Atomic Energy Research Institute, 989-111 Daedeok-daero, Yuseong-gu, Daejeon 305-353, Republic of Korea \\ Correspondence should be addressed to Hyoung Tae Kim; kht@kaeri.re.kr
}

Received 8 October 2014; Accepted 19 January 2015

Academic Editor: Eugenijus Ušpuras

Copyright ( 92016 H. T. Kim and B. W. Rhee. This is an open access article distributed under the Creative Commons Attribution License, which permits unrestricted use, distribution, and reproduction in any medium, provided the original work is properly cited.

\begin{abstract}
Korea Atomic Energy Research Institute (KAERI) started the experimental research on moderator circulation as one of a the national research and development programs from 2012. This research program includes the construction of the moderator circulation test (MCT) facility, production of the validation data for self-reliant computational fluid dynamics (CFD) tools, and development of optical measurement system using the particle image velocimetry (PIV). In the present paper we introduce the scaling analysis performed to extend the scaling criteria suitable for reproducing thermal-hydraulic phenomena in a scaleddown CANDU- (CANada Deuterium Uranium-) 6 moderator tank, a manufacturing status of the 1/4 scale moderator tank. Also, preliminary CFD analysis results for the full-size and scaled-down moderator tanks are carried out to check whether the moderator flow and temperature patterns of both the full-size reactor and scaled-down facility are identical.
\end{abstract}

\section{Introduction}

The CANDU-6 reactor has a square array of horizontal fuel channels surrounded by heavy water moderator contained in a horizontal, cylindrical tank called a calandria. Each fuel channel consists of two concentric tubes: a pressure tube (PT) inside a calandria tube (CT), with a gap that contains $\mathrm{CO}_{2}$ insulating gas. During normal operation, the moderator water absorbs about $5 \%$ of the reactor thermal power as a result of absorbing neutron kinetic energy and gamma radiation generated by the fuel and in-core structures (guide tubes, calandria tubes, etc.). The moderator water is pumped out of the outlet ports of calandria and cooled through heat exchanges and then returned to the calandria via a set of inlet nozzles. However, following a large loss of coolant accident (LOCA) without emergency core injection (ECI), the PT significantly heats up as a result of the initial power pulse and degraded coolant flow. Consequently, some PTs balloon and come into contact with the CTs. Following this PT/CT contact, the PTs are cooled as they transfer some of the absorbed heat to the moderator via conduction at contact locations. As long as a sustained CT dryout does not occur, the CT surface temperature remains below the creep threshold temperature and no further deformation is expected. Consequently, a sufficient condition to ensure the fuel channel integrity following a large LOCA is the avoidance of a sustained CT dryout. If the moderator available subcooling at the onset of a large LOCA is greater than the subcooling requirements [1], a sustained CT dryout is avoided. The subcooling requirements are determined from a set of experiments known as the fuel channel contact boiling experiments [2]. The difference between available subcooling and required subcooling is called subcooling margins. The local temperature of the moderator is a key parameter in determining the available subcooling. To predict the local temperature in the calandria, numerous experimental and numerical researches have been carried out.

Koroyannakis et al. [3] experimentally investigated the flow phenomena generated by the inlet jet and internal heating of a fluid in a calandria-like cylindrical vessel of SPEL (Sheridan Park Engineering Laboratory). These experimental results give an intuitional observation on the relationship between the moderator circulation pattern and the inlet flow rate and heat load.

Huget et al. [4] performed experimental and numerical investigation of the moderator circulation test in a twodimensional (2D) slice-type facility at the Stern Laboratories 
Inc. in Canada. It was a useful intermediate step to the complicated three-dimensional (3D) test and provided preliminary information on moderator circulation flow patterns and assisted in tuning instrumentation, data recording, and data analysis techniques needed for the massive data collected in the $3 \mathrm{D}$ test.

The experimental programs at Chalk River Laboratories in Canada comprised a number of single-effect and integraleffect tests. The separate-effect and component experiments, performed in specially designed test sections and test loop configurations, include the round jet development test, moderator inlet diffuser characterization, tube bank pressure loss experiments, wall jet development studies, and buoyant jet experiments. Khartabil et al. [5] conducted 3D moderator circulation test in the main moderator test facility (MTF). The 1/4 scale calandria vessel of MTF was fitted with 480 electrically heated tubes to simulate reactor calandria tubes. Power distributions in the heated tubes were designed to represent reactor conditions in both axial and radial directions. The temperature measurements in the MTF provided the local temperature at more than 300 locations in the test facility. In addition to temperature measurements, the MTF tests also included 3D velocity and turbulence measurements using laser Doppler anemometry (LDA) instrumentation. The MTF test program provided data for the validation of the computational fluid dynamics (CFD) code, MODTURC_CLAS [6] which is employed by the CANDU industry to predict moderator flow and temperature distributions for a moderator subcooling analysis.

Korea Atomic Energy Research Institute (KAERI) started the experimental research on moderator circulation as one of the national research and development programs from 2012. The motivation of this research is to secure the experimental data base to validate the CFD code for licensing. This research program includes construction of moderator circulation test (MCT) facility, production of the validation data for selfreliant CFD tools, and development of optical measurement system using the particle image velocimetry (PIV) and laser induced fluorescence (LIF) techniques. In this paper we present the scaling analysis performed to obtain the scaling criteria suitable for reproducing thermal-hydraulic phenomena of a full-size CANDU-6 moderator tank in 1/40, 1/8, and $1 / 4$ small-scale model tests [7]. The reason why $1 / 40$ and $1 / 8$ scaled-down models are studied to identify the potential problems of the flow visualization and measurement expected in the main 1/4 scale MCT facility is concluded. The technical description of the selected 1/4 scale moderator tank and preliminary CFD analysis results are shown in this paper. The results of CFD analysis provide the flow, thermal, and heating boundary conditions with which the various flow patterns expected in the full-size CANDU-6 moderator tank can be reproduced in the experiment.

\section{Scaling Analysis for CANDU-6 Moderator Tank}

2.1. Scaling Approach. The purpose of the present scaling analysis is to derive a set of scaling criteria suitable for reproducing thermal-hydraulic phenomena in a scaled-down CANDU-6 moderator tank similar to that in a full-size power plant during steady state operation and accident conditions [5-7]. The major phenomena of the author's interests are the moderator flow circulation and temperature inside the moderator tank during steady state condition and the major accident conditions.

In the scaling analysis, the governing equations are initially transformed into dimensionless equations based on the representative characteristic values of the basic design such as the time, tank diameter, inlet fluid velocity, and average temperature rise, and 3 dimensionless numbers, $\mathrm{Re}, \mathrm{Pr}$, and Ar, are identified as those characterizing the major phenomena of the system. The relevant boundary conditions are then identified in a dimensionless form and compatibility of keeping these 3 dimensionless numbers, the volumetric heat source distribution, and the boundary conditions in dimensionless forms the same for both fullsize and scaled-down tanks are examined, and some of them which are less important are relaxed so as to find a practically implementable set of constraints. The size of the scaled-down moderator tank and the corresponding inlet velocity are then found for the available power supply capacity. As an example, the present geometric scaling ratio is $1 / 4$ with a power supply capacity of about $1.5 \mathrm{MW}$ as compared to $100 \mathrm{MW}$ for the fullsize reactor.

2.2. Scaling Criteria. According to a previous study by Khartabil et al. [5], the following dimensionless governing equations can be derived:

$$
\begin{gathered}
\nabla^{*} V^{*}=0 \\
\frac{\partial V^{*}}{\partial t^{*}}+\left(V^{*} \cdot \nabla^{*}\right) V^{*}=-\nabla^{*} P^{*} \frac{1}{\operatorname{Re}}\left(\nabla^{*}\right)^{2} V^{*}-\operatorname{Ar} \frac{g}{|g|} T^{*}, \\
\frac{\partial T^{*}}{\partial t^{*}}+\left(V^{*} \cdot \nabla^{*}\right) T^{*}=\frac{1}{\operatorname{Re} \operatorname{Pr}}\left(\nabla^{*}\right)^{2} T^{*}+q^{*}
\end{gathered}
$$

To obtain above dimensionless equations, the dimensionless variables are defined as

$$
\begin{gathered}
V^{*}=\frac{V}{U_{i}}, \quad T^{*}=\frac{\left(T-T_{o}\right)}{\Delta T}, \\
P^{*}=\frac{P}{\rho_{\mathrm{ref}} U_{i}^{2}}, \\
t^{*}=\frac{t U_{i}}{D}, \quad \nabla^{*}=D \nabla,
\end{gathered}
$$

and then the following dimensionless numbers are defined as

$$
\begin{gathered}
\operatorname{Pr}=\frac{\mu C_{p}}{k}, \\
\operatorname{Re}=\frac{\rho_{\mathrm{ref}} U_{i} D}{\mu},
\end{gathered}
$$




$$
\begin{gathered}
A r=\frac{g \beta_{\mathrm{ref}} \Delta T D}{U_{i}^{2}}, \\
q^{*}=\frac{q D}{\rho_{\mathrm{ref}} C_{p} U_{i} \Delta T},
\end{gathered}
$$

where $V$ = fluid velocity $(\mathrm{m} / \mathrm{s}), U_{i}=$ inlet velocity magnitude $(\mathrm{m} / \mathrm{s}), \rho_{\text {ref }}=$ reference density $\left(\mathrm{kg} / \mathrm{m}^{3}\right), P=$ fluid pressure minus the static head at the reference density $(\mathrm{Pa}), T=$ fluid temperature $\left({ }^{\circ} \mathrm{C}\right), T_{o}=$ outlet fluid temperature $\left({ }^{\circ} \mathrm{C}\right)$, $\Delta T=$ temperature difference between inlet and outlet $\left({ }^{\circ} \mathrm{C}\right)$, $t=$ time (s), $D=$ vessel diameter $(\mathrm{m}), g=$ gravity constant $\left(\mathrm{m} / \mathrm{s}^{2}\right), \mu=$ fluid dynamic viscosity $(\mathrm{kg} / \mathrm{m}-\mathrm{s}), k=$ thermal conductivity $\left(\mathrm{W} / \mathrm{m}-{ }^{\circ} \mathrm{C}\right), C_{p}=\operatorname{specific}$ heat $\left(\mathrm{J} / \mathrm{kg}-{ }^{\circ} \mathrm{C}\right), \beta_{\text {ref }}=$ reference thermal expansion coefficient, and $q=$ local heat generation rate $\left(\mathrm{W} / \mathrm{m}^{3}\right)$, a function of space and time.

If the same working fluid is used for both the full-size and the scaled-down facilities, Pr in (5) can be well conserved. The Re in (6) is defined by the system parameters such as the inlet velocity and the tank diameter and shown to be larger than $10^{4}$ for both the full-size and the scaled-down facilities. This Re number is sufficiently large to guarantee that the relative contributions of the diffusion processes represented by the Laplace operator on $V^{*}$ and $T^{*}$ to the overall balances in (2) and (3) are negligible and, thus, the Re number equivalence can be abandoned.

The dimensionless volumetric heat source $\left(q^{*}\right)$ and $\mathrm{Ar}$ would depend on $\Delta T, U_{i}$, and $D$. Therefore, if any combination of $\Delta T, U_{i}$, and $D$ for which $\operatorname{Ar}$ and $q^{*}$ may be kept the same for both facilities, the hydrodynamic similarity inside the moderator tank is maintained.

2.3. Scaling Procedure. The scaling of the moderator is to determine the tank size, nozzle size, heater power, inlet massflow rate, and inlet and outlet temperature of the calandria. Given the geometry scaling at the beginning of scaling, the scaling can be done to determine the heater power, massflow rate, and inlet and outlet temperature using the integral scaling of natural circulation.

(1) Establish conditions and geometry of a full-size calandria to be scaled down. Check whether the given conditions of calandria, $\Delta T$, and mass-flow rate of the full-size reactor using the energy balance equation are appropriate.

(2) For an example of 1/4 scale, all linear dimensions are scaled simply by the same factor of $1 / 4$. The volume scale will be $1 / 64$. The number of inlet nozzles is the same as the full-size reactor but can be scaled with a scaled number (in this case, an equivalent hydraulic diameter may be applied).

(3) Choose an appropriate $\Delta T=T_{\text {out }}-T_{\text {in }}$, as high as possible for the best measurement resolution while keeping within the pumping and heating constraints.

(4) Calculate properties $(\beta, \rho)$ for the full-size and scaleddown model using averaged temperatures of $T_{\text {in }}$ and $T_{\text {out }}$ and estimated pressures of the full-size and scaled-down model.
(5) Using the given mass-flow rate and nozzle configuration for the full-size reactor, calculate the velocity in the nozzle of the full-size reactor.

(6) Calculate the Ar number of the full-size reactor. In this number, the length scale is the calandria vessel diameter, and the velocity is the inlet velocity of the fluid at the nozzles.

(7) Using the similarity of Ar number of the full-size reactor, calculate the velocity in the nozzle of the model with the scaled nozzle diameter by the following scaling ratio:

(i) scaling ratio of the inlet velocity:

$$
U_{i R}=\left(\frac{\beta_{R} \Delta T_{R} D_{R}}{\operatorname{Ar}_{R}}\right)^{0.5},
$$

where subscript $R$ is the ratio of scaled-down model to full-size reactor.

(8) Calculate the mass-flow rate in the nozzles of the model using the velocity and scaled-down nozzle configuration.

(9) Calculate the power of the scaled-down model using the energy balance equation and $\Delta T$. Check the power of the model whether it is available in the power supply system for the test facility.

(10) Check the volumetric power of the full-size and scaled-down model; distortion may be inevitable.

(11) Calculate the dimensionless volumetric heat source numbers for the full-size and scaled-down model, and they will give the same values.

2.4. Scaling Results. According to the present scaling procedures, the main design parameters for the small scales of $1 / 40$ and 1/8 test facilities and the main 1/4 scale MCT test facility can be determined as shown in Table 1 . All scaled-down models are preserving the dimensionless parameters of Ar and $q^{*}$. For the $1 / 40$ scaled-down model, the porosity, which is the ratio of fluid volume to total volume, is maintained while the tube diameter and the tube pitch are not linearly scaled due to the geometric limitation of the manufacturing and flow visualization.

If we reduce the volumetric power while preserving the dimensionless parameters of Ar and $q^{*}$, total heater power and $\Delta T$ (temperature difference between inlet and outlet) can be reduced as shown in Figure 1. The heater power becomes $495 \mathrm{~kW}$ with $8^{\circ} \mathrm{C}$ of $\Delta T$.

\section{Description of Moderator Circulation Test (MCT) Facility}

Moderator circulation test (MCT) facility installed at KAERI in 2014 is the large-scale facility designed to reproduce the important characteristics of moderator circulation in a CANDU-6 calandria under a range of operating conditions. It is reduced in a 1/4 scale and a moderator test vessel is built 
TABLE 1: Comparison of the main design parameters for the full-size and scaled-down models.

\begin{tabular}{|c|c|c|c|c|}
\hline Model & Full-size CANDU-6 & $1 / 40$ scale & $1 / 8$ scale & $1 / 4$ scale \\
\hline Reference heating power & $1 \times 10^{5} \mathrm{~kW}$ & $1.839 \mathrm{~kW}$ & $214.6 \mathrm{~kW}$ & $1,566 \mathrm{~kW}$ \\
\hline Tank diameter $(D)$ & $7.6 \mathrm{~m}$ & $0.181 \mathrm{~m}$ & $0.98 \mathrm{~m}$ & $1.9 \mathrm{~m}$ \\
\hline $\begin{array}{l}\text { Area of an inlet nozzle } \\
(1 \text { of } 8)\end{array}$ & $5.7456 \times 10^{-2} \mathrm{~m}^{2}$ & $3.258 \times 10^{-5} \mathrm{~m}^{2}$ & $9.506 \times 10^{-4} \mathrm{~m}^{2}$ & $3.591 \times 10^{-3} \mathrm{~m}^{2}$ \\
\hline Inlet and outlet temperature difference $(\Delta T)$ & $23^{\circ} \mathrm{C}$ & $10^{\circ} \mathrm{C}$ & $15^{\circ} \mathrm{C}$ & $17^{\circ} \mathrm{C}$ \\
\hline Calandria tube (heater) diameter & $0.131 \mathrm{~m}$ & $0.017 \mathrm{~m}$ & $0.017 \mathrm{~m}$ & $0.033 \mathrm{~m}$ \\
\hline Tube pitch & $0.286 \mathrm{~m}$ & $0.037 \mathrm{~m}$ & $0.037 \mathrm{~m}$ & $0.072 \mathrm{~m}$ \\
\hline Number of tubes & 380 & 12 & 380 & 380 \\
\hline Archimedes number (Ar) & 0.21 & 0.21 & 0.21 & 0.21 \\
\hline Dimensionless heat $\left(q^{*}\right)$ & 0.013 & 0.013 & 0.013 & 0.013 \\
\hline Porosity in the tube bank & 0.83 & 0.83 & 0.83 & 0.83 \\
\hline Inlet flow rate & $1,019 \mathrm{~kg} / \mathrm{sec}$ & $0.042 \mathrm{~kg} / \mathrm{sec}$ & $0.863 \mathrm{~kg} / \mathrm{sec}$ & $22.3 \mathrm{~kg} / \mathrm{sec}$ \\
\hline
\end{tabular}

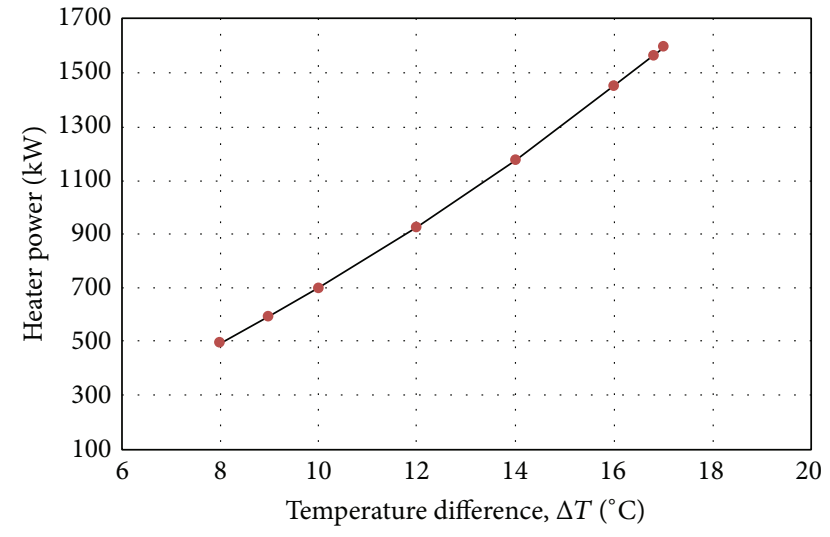

FIgURE 1: Choice of heater power with temperature difference $(\Delta T)$ for $1 / 4$ scale model.

to the specifications of the CANDU-6 reactor design, where a working fluid is subcooled water with atmospheric pressure.

The MCT consists of the primary and secondary water circuit as the same as CANDU-6 moderator system. The primary circuit, as shown in Figure 2(a), includes a moderator tank, a circulating pump, a heat exchanger, and intermediate pipe lines. The circulating pump enforces the cold water to enter the tank through eight nozzles, four nozzles at each side, and heated water exits from two outlet pipes at the bottom of the tank. When water flows through the heat exchanger tubes, primary hot water is cooled by the secondary side water circulating through the external cooling tower. Then cold water comes back to the inlet nozzles via a circulating pump.

The inner diameter and axial length of test vessel are $1900 \mathrm{~mm}$ and $1500 \mathrm{~mm}$, respectively. The main design parameters of MCT are listed in Table 1. The test vessel is equipment with 380 acrylic pipes (for nonheating test) or electric heaters simulating the horizontal fuel channels (for heating test). The electric heaters are designed to provide axial and radial power profiles representative of CANDU-6 power profiles. An axial power profile is a symmetric cosine profile with a peak-to-average ratio of 1.4. A radial power profile is created by arranging the heaters in two concentric power zones, with an individual heat power ratio of 1.4 between the inner and the outer zones.

Tank walls with $5 \mathrm{~mm}$ of thickness and other support structures are made of SUS 304 stainless steel. Several transparent sections are incorporated into the vessel to facilitate flow visualization tests. The front and rear side of both ends of the tank are individually made of a polycarbonate plate with $15 \mathrm{~mm}$ thickness. These plates are sealed by two stainless steel flanges (each of $35 \mathrm{~mm}$ and $25 \mathrm{~mm}$ thickness) with a silicone O-ring placed between the plate and flange as shown in Figure 2. Eight view ports are installed to each side of the tank wall.

The MCT facility is thoroughly instrumented to provide data suitable for code validation. The test conditions are tightly controlled using a data acquisition and control system (DAS). The instrumentation can be divided into test vessel and loop instrumentation.

The velocity and temperature profiles in the test vessel are measured by the particle image velocimetry (PIV) and the laser induced fluorescence (LIF) measurement systems, respectively. An access tank $(950 \mathrm{~mm} \times 650 \mathrm{~mm})$ on top of the vessel allows the exposure of the laser beam as well as thermocouple measurements inside the vessel.

The PIV measurement system consists of a TSI PowerView Plus 2MP CCD camera and a dual Nd-Yag. The double pulse laser operates at $15 \mathrm{~Hz}$ with a $200 \mathrm{~mJ} / \mathrm{pulse}$. The laser beam was modified using a spherical and cylindrical lens combination to form a thin light sheet on the $x$ - $y$ plane. $10 \mu \mathrm{m}$ sized silver coated hollow spheres were used as flow tracing particles. The 2MP CCD camera records scattering light from the tracer particles. INSIGHT $4 \mathrm{G}$ software is used to control the image capture and perform the data analysis.

The thermocouple rods are inserted in the $7 \times 5$ arrays of guide ports (Figure 2(b)) penetrating the upper part of the tank wall and the access tank. The thermocouple measurements can be used for auxiliary temperature measurements as well as calibration of the LIF measurements. The loop instrumentation consists of flow rate, temperature, and pressure measurements. The multistage centrifugal pump is used to circulate water in the primary loop and a total flow 


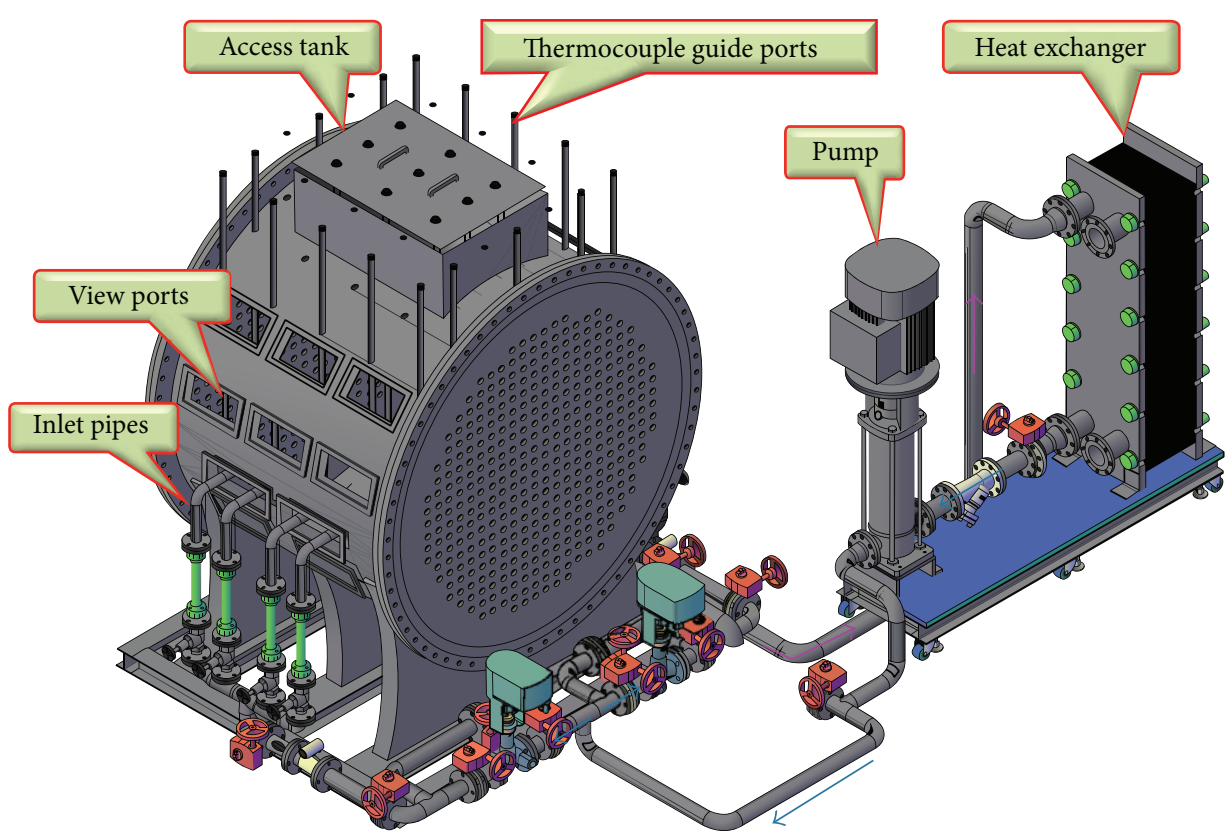

(a) Overview of the primary water circuit of MCT

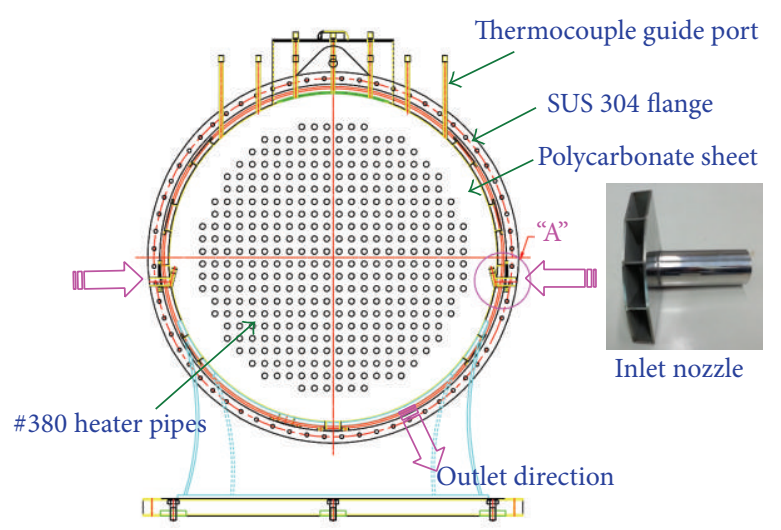

(b) Cross-sectional view of the moderator tank

FIGURE 2: Geometric configuration of the MCT facility.

rate is adjusted by the inverter control. The flow rate to each side of inlet nozzles is measured by a vortex flow meter and the flow split to each side is automatically controlled by 3 way valve. The flow rates to individual inlet nozzles can be monitored and adjusted by rotameters. The inlet and outlet temperatures are measured by T-type thermocouples. The inlet temperature is controlled by adjusting bypass flow in the secondary side of the heat exchanger. Pressure tap can be used to measure the pressure drop between the inlet and outlet of the pump.

\section{Preliminary CFD Analysis for MCT Test}

Two numerical CFD simulations for the full-size and scaleddown moderator tanks are carried out to check whether the moderator flow and temperature patterns of both the full-size reactor and scaled-down facility are identical.
4.1. CFD Model. A commercial CFD code, ANSYS CFX version 14.0 [8], is used to simulate the full-size reactor and MCT for the normal operating condition.

The CFX code is based on the finite volume method (FVM) modified with the shape function used in finite element methods (FEM) to make the construction of a nodecentered computation possible [9].

The governing equations consist of conservative laws on mass, momentum, and energy. They are written as follows in tensor form:

$$
\begin{gathered}
\frac{\partial \rho}{\partial t}+\frac{\partial}{\partial x_{j}}\left(\rho U_{j}\right)=0 \\
\frac{\partial}{\partial t}\left(\rho U_{i}\right)+\frac{\partial}{\partial x_{j}}\left(\rho U_{i} U_{j}\right)=-\delta_{i, j} \frac{\partial p}{\partial x_{j}}+\frac{\partial \tau_{i, j}}{\partial x_{j}}+S_{M i}
\end{gathered}
$$




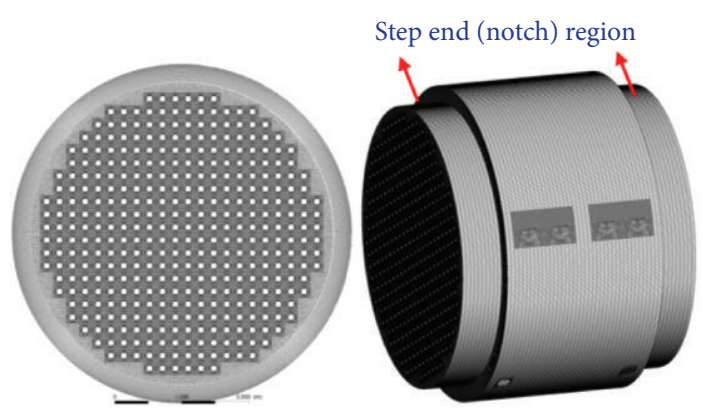

(a) Full-size model (CANDU-6)

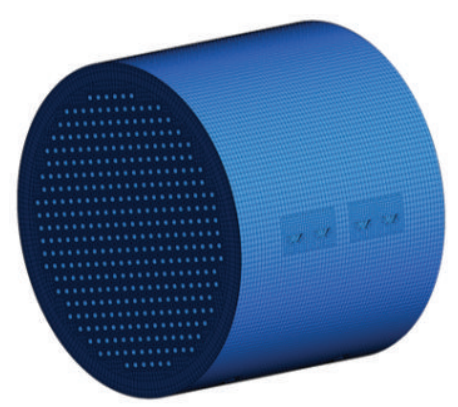

(b) Scaled-down model (MCT)

FIgURE 3: Mesh configuration for the full-size and scaled-down model.

$$
\begin{aligned}
& \frac{\partial}{\partial t}\left(\rho h_{\mathrm{tot}}\right)-\frac{\partial p}{\partial t}+\frac{\partial}{\partial x_{j}}\left(\rho U_{j} h_{\mathrm{tot}}\right) \\
& =\frac{\partial}{\partial x_{j}}\left(\lambda \frac{\partial T}{\partial x_{j}}\right)+\frac{\partial}{\partial x_{j}}\left(U_{j} \tau_{i, j}\right)+U_{i} S_{M i}+S_{E}
\end{aligned}
$$

where $\rho, U_{j}, p, \tau_{i, j}$, and $T$ are density, velocity vector, pressure, shear stress, and temperature, and so forth; the coefficient $\lambda$ is thermal conductivity. The shear stress tensor in (11) by the Navier-Stokes equation and total enthalpy, $h_{\text {tot }}$, in (12) by energy equation are defined as

$$
\begin{gathered}
\tau_{i . j}=\mu\left\{\left(\frac{\partial U_{i}}{\partial x_{j}}+\frac{\partial U_{j}}{\partial x_{i}}\right)-\frac{2}{3} \delta_{i, j} \frac{\partial U_{i}}{\partial x_{j}}\right\}, \\
h_{\mathrm{tot}}=h+\frac{1}{2} U_{j}^{2},
\end{gathered}
$$

where the coefficient $\mu$ is viscosity, and $h=e+p / \rho$; $e$ is the internal energy per unit mass.

The $k-\varepsilon$ model with scalable wall functions is applied for turbulence model. The incident turbulence intensity is assumed to be $5 \%$.

In the convergence, the relative tolerance of time iterative error is set to $10^{-5}$ for the steady solution.

The accuracy on both time and space is of second order.

The $y^{+}$value is defined as, $\Delta y$, the normal length of the first grid neighbouring the wall:

$$
y^{+}=\Delta y \sqrt{\left.\frac{\rho}{\mu} \frac{\Delta u_{t}}{\Delta y}\right|_{y=y_{w}},}
$$

where $u_{t}$ is the tangentially transformed velocity component along the wall. To get the proper result of computation without wall functions, the dimensionless wall distance should be guaranteed $y^{+}<1$ as in the whole computational domain.

However, the required number of grids can be reduced with the use of wall functions [9]:

$$
y^{+}=\max \left(\frac{\rho}{\mu} \Delta y C_{\mu}^{1 / 4} \sqrt{k}, 11.06\right),
$$

where $k$ is the turbulence kinetic energy and $C_{\mu}$ is a coefficient. Therefore, the grids in the range of $y^{+}<11.06$ are neglected due to being unnecessary, and $y^{+}<300$ is sufficient for the capture of the outer layer in a low Reynolds number flow for engineering computation. The $y^{+}$value is maintained $y^{+}<300$ for all grid points.

4.2. Mesh Generation. ICEM CFD version 14.0 [10] is used to generate the mesh of moderator tank and boundary surfaces. Hexagonal mesh (around the tube region) and unstructured mesh (inlet nozzle region) are combined to produce a total of 638,000 and 658,000 mesh elements for the full-size and scaled-down model, respectively. The full-size and scaleddown model use the same mesh model except the step end region as shown in Figure 3.

4.3. Boundary Conditions. Flow boundary condition is applied to 8 inlet surfaces and outlet boundary condition to 2 outlet surfaces. Moderator enters the calandria with the velocity of 4.0 and $1.0 \mathrm{~m} / \mathrm{s}$ through each inlet nozzle for fullsize and scaled-down model, respectively. Volumetric heat source is set to fluid domain. An axial power profile is a symmetric cosine profile with a peak-to-average ratio of 1.4. A radial power profile is simplified into two concentric power zones, with a heat power ratio of 1.4 between the inner and the outer zones.

\subsection{Calculation Results}

4.4.1. Temperature Distribution. Each simulation is carried out with 3,000 iterations from initial condition. The results of temperature and velocity profiles are unsteady but show a unique pattern. Figure 4 shows the temperature distribution inside the moderator tank for CANDU-6 and MCT. The temperature contours for both cases show a typically asymmetric pattern, which is called a mixed-flow due to a balance of momentum and buoyancy forces.

Figure 5 shows that the axial temperature distributions for both cases are not uniform and the hot temperature zone is pushed down by cold impinging jets from the inlet nozzles.

4.4.2. Velocity Distribution. The velocity vectors for full-size and scaled-down models are compared in Figures 6 and 7. The impingement point is located at the top right-hand side of the tank for both cases (Figure 6). The maximum 


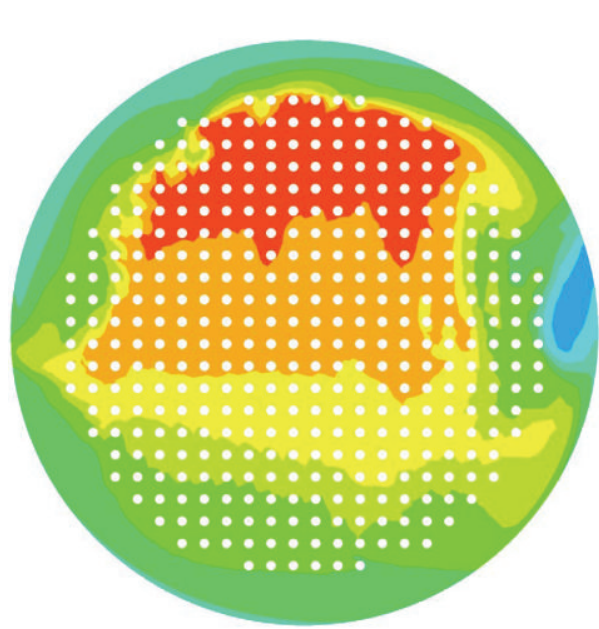

(m)

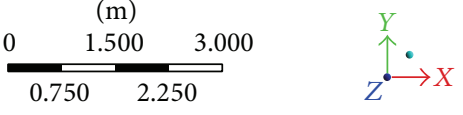

(a) Full-size model (CANDU-6)

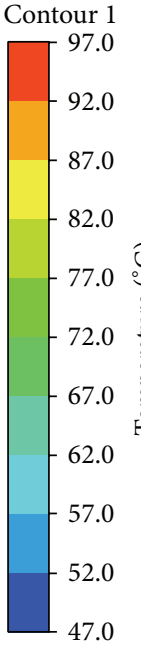

47.0

FIGURE 4: Temperature distribution on the axial center plane.

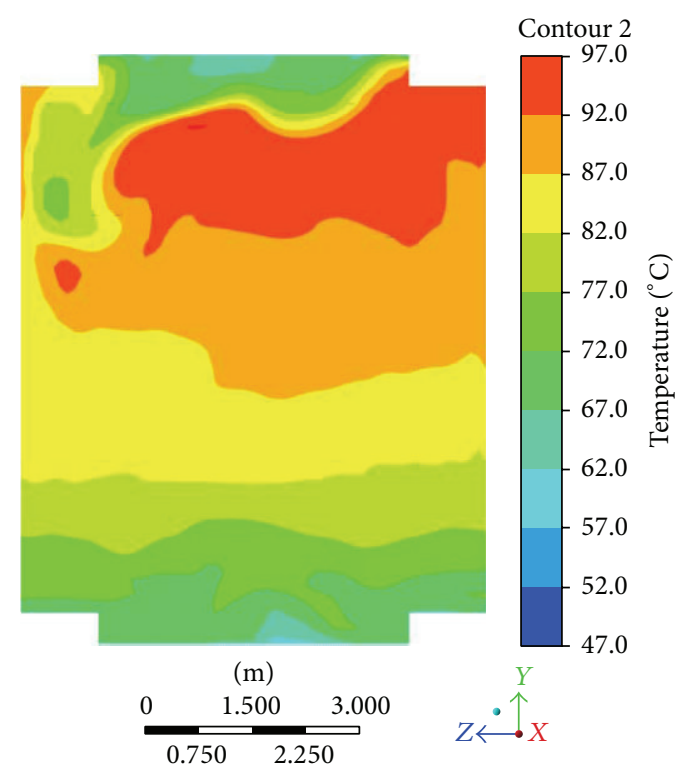

(a) Full-size model (CANDU-6)

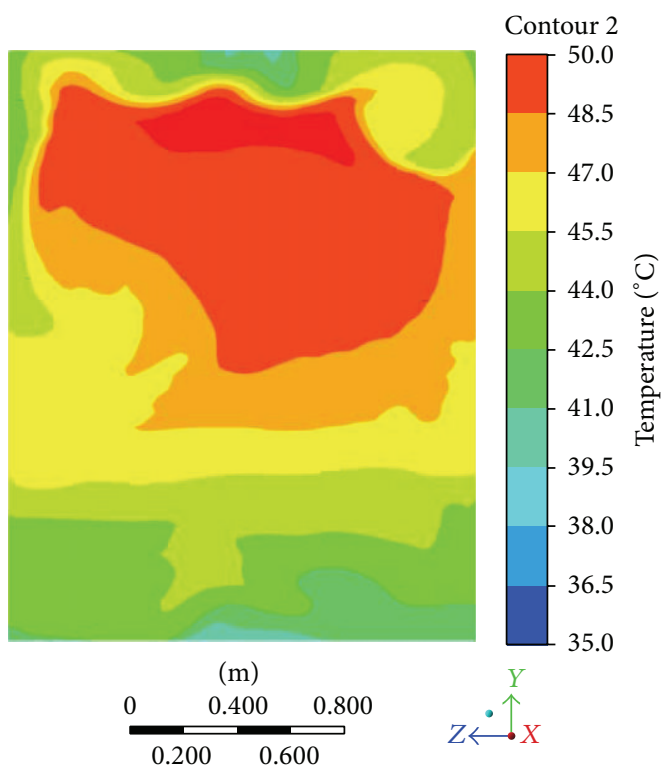

(b) Scaled-down model (MCT)

FIgURE 5: Temperature distribution along the axial direction.

velocity vectors on the axial plane ( $y-z$ plane in Figure 7$)$ are smaller than those on the cross-sectional plane $(x-y)$ plane in Figure 6).

\section{Conclusions}

The $1 / 4$ scale of moderator circulation test (MCT) facility has been manufactured as the design parameters determined by the scaling analysis to reproduce the moderator circulation behaviour in the CANDU-6 calandria tank. It includes a primary circulation loop (pipe lines, a primary side pump, a heat exchanger, valves, and flow meters) and a secondary side loop (pipe lines, a secondary side pump, and an external cooling tower). The loop leakage test and nonheating test have been performed.

From the scaling analysis the representative characteristic values of the basic design such as the time, tank diameter, inlet fluid velocity, and average temperature rise are determined 


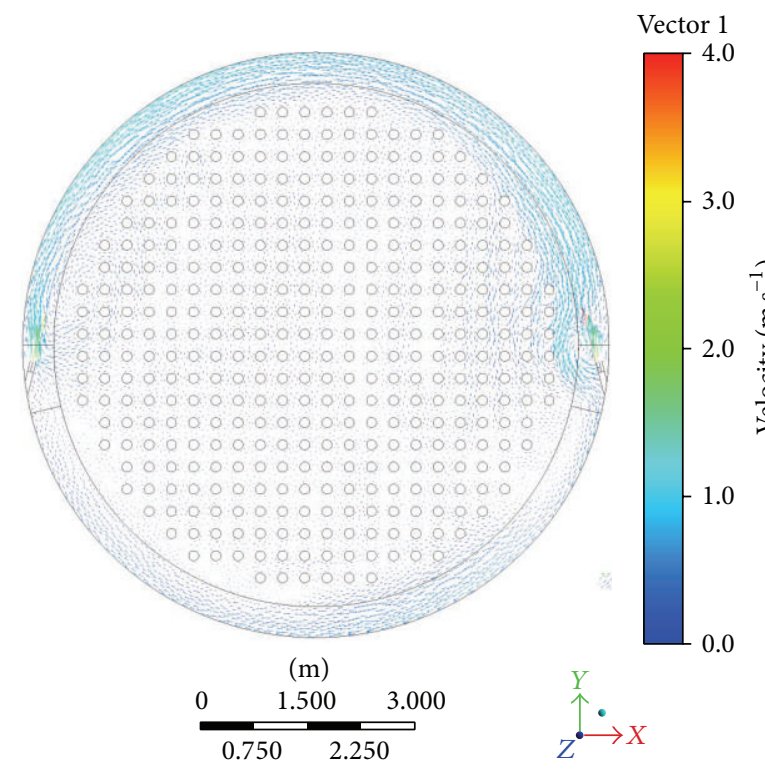

(a) Full-size model (CANDU-6)

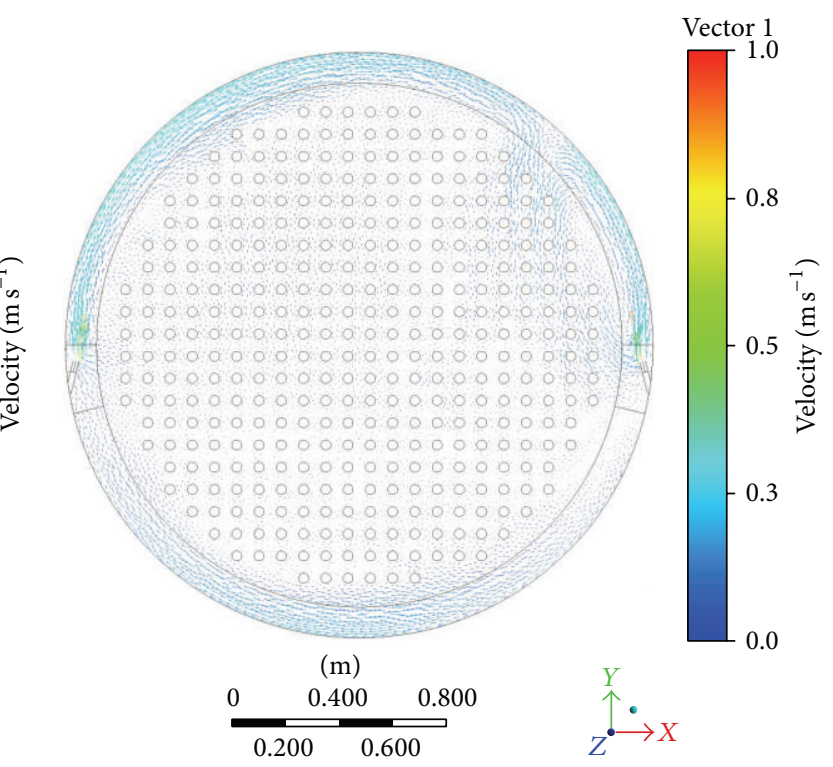

(b) Scaled-down model (MCT)

FIGURE 6: Velocity vector on the axial center plane.

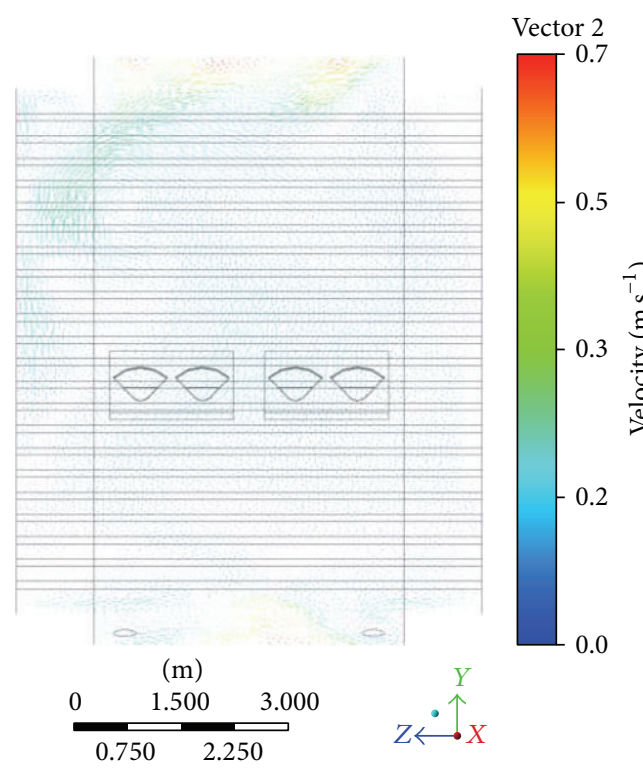

(a) Full-size model (CANDU-6)

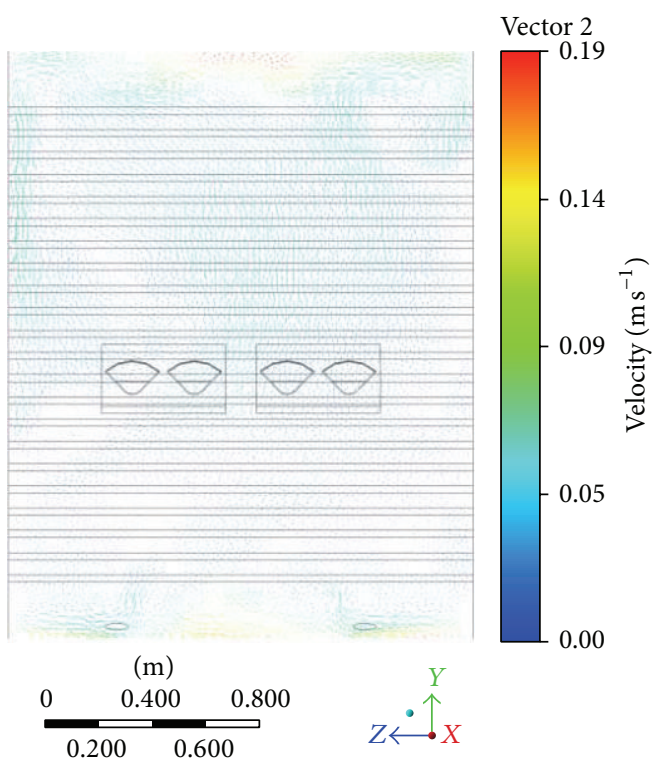

(b) Scaled-down model (MCT)

FIGURE 7: Velocity vector along the axial direction.

to design the scaled-down model. As a way to confirm the similarity between CANDU-6 reactor and MCT facility, two numerical CFD simulations have been carried out with the boundary conditions at the inlet and outlet ports and on the walls of the solid structures, such as the moderator tank and calandria tubes, which were derived from those of the dimensionless scales to check if the moderator flow and temperature patterns of both the full-size reactor and scaleddown facilities are identical or at least similar. The results of both simulations are compared with each other to study the effects of scaling on the moderator flow and temperature patterns. There is no significant difference of results between the full-size and scaled-down model.

For future works, optical measurement results for the isothermal test in the MCT facility will be compared with the CFD predictions. After isothermal test, acrylic pipes will be replaced by heater rods for heating test. Test data obtained from the moderator circulation test facility can be utilized for development and validation of moderator models of the CFD codes. 


\section{Conflict of Interests}

The authors declare that there is no conflict of interests regarding the publication of this paper.

\section{Acknowledgment}

This work was supported by the National Research Foundation of Korea (NRF) grant funded by the Korea Government (Ministry of Science, ICT, and Future Planning) (no. NRF2012M2A8A4025964).

\section{References}

[1] H. Z. Fan, R. Aboud, P. Neal, and T. Nitheanandan, "Enhancement of the moderator subcooling margin using glass-peened calandria tubes in CANDU reactors," in Proceedings of the 30th Annual Canadian Nuclear Society Conference and 33rd CNS/CNA Student Conference, pp. 2150-2163, Calgary, Canada, June 2009.

[2] G. E. Gillespie, "An experimental investigation of heat transfer from a reactor fuel channel: to surrounding water," in Proceedings of the 2nd Annual Conference of the Canadian Nuclear Society, pp. 157-163, Ottawa, Canada, 1981.

[3] M. S. Quraishi, D. Koroyannakis, and W. F. Waters, "A study of combined forced and natural convection flow using an analytical indicator flow visualization technique," in Proceedings of the 3rd International Symposium on Flow Visualization, Ann Arbor, Mich, USA, September 1983.

[4] R. G. Huget, J. K. Szymanski, and W. I. Midvidy, "Experimental and numerical modelling of combined forced and free convection in a complex geometry with internal heat generation," in Proceedings of the 9th International Heat Transfer Conference, Jerusalem, Israel, 1990.

[5] H. F. Khartabil, W. W. R. Inch, J. Szymanski, D. Novog, V. Tavasoli, and J. Mackinnon, "Three-dimensional moderator circulation experimental program for validation of CFD code MODTURC_CLAS," in Proceedings of the 21st Nuclear Simulation Symposium, Ottawa, Canada, September 2000.

[6] A. Sarchami, N. Ashgriz, and M. Kwee, "Three dimensional numerical simulation of a full scale CANDU reactor moderator to study temperature fluctuations," Nuclear Engineering and Design, vol. 266, pp. 148-154, 2014.

[7] H. T. Kim, B. W. Rhee, J. E. Cha, and H. L. Choi, "Status of moderator circulation test at Korea Atomic Energy Research Institute," in Proceedings of the Korea Nuclear Society Spring Meeting, Gwangju, Republic of Korea, May 2013.

[8] ANSYS, ANSYS CFX-14.0 User Manual (Embedded in the Software Package), ANSYS, Canonsburg, Pa, USA, 2012.

[9] ANSYS Inc, ANSYS CFX-14.0 Solver Theory Guide (Embedded in the Software Package), ANSYS Inc, Canonsburg, Pa, USA, 2012.

[10] ANSYS, ANSYS ICEM CFD-14.0 User Manual (Embedded in the Software Package), ANSYS, Canonsburg, Pa, USA, 2012. 

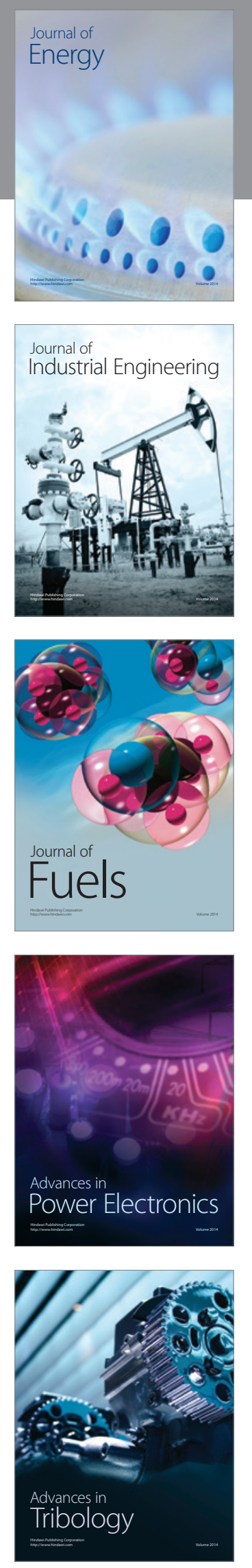
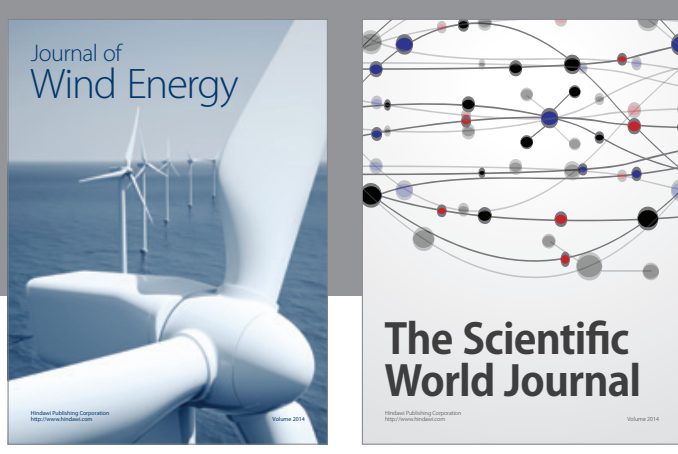

The Scientific World Journal
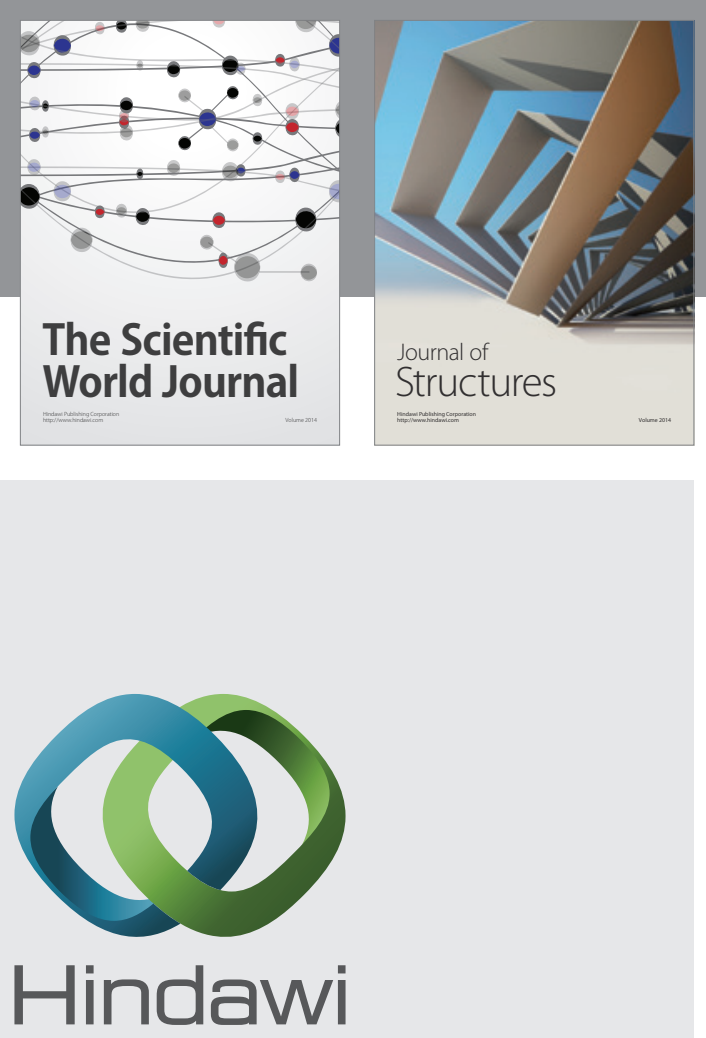

Submit your manuscripts at

http://www.hindawi.com
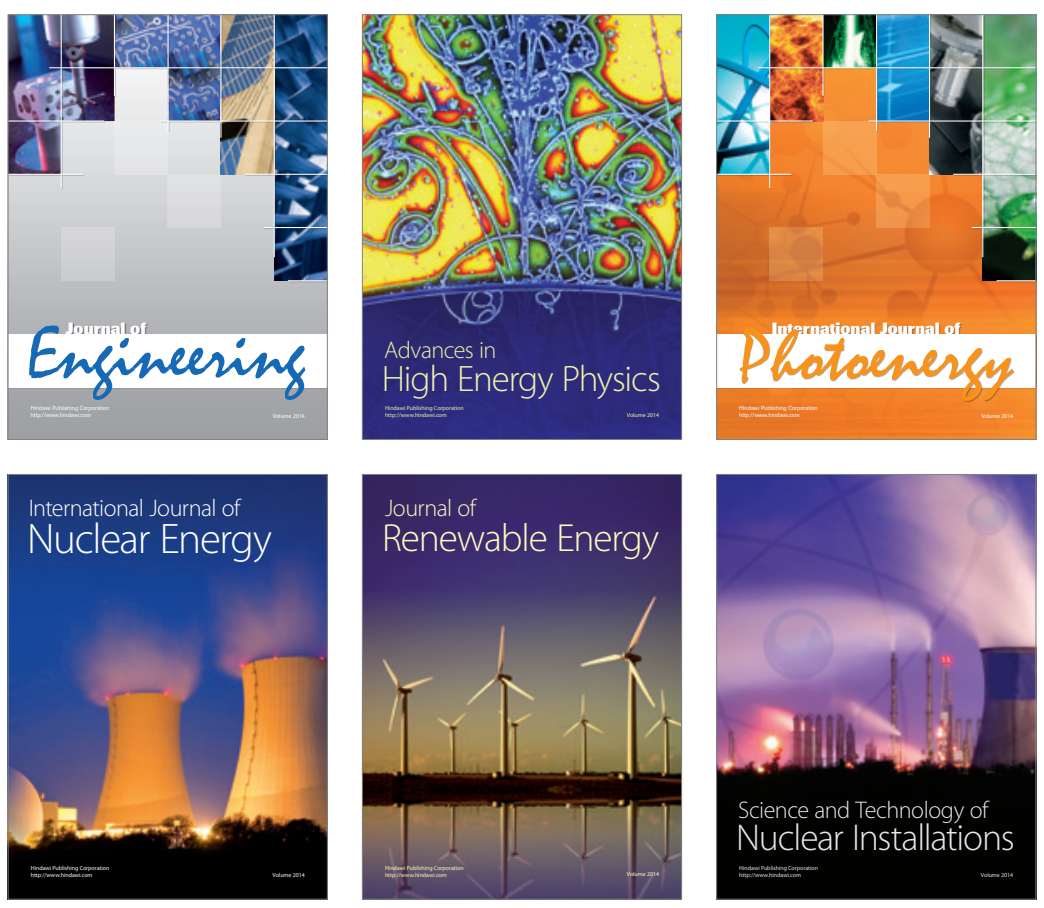
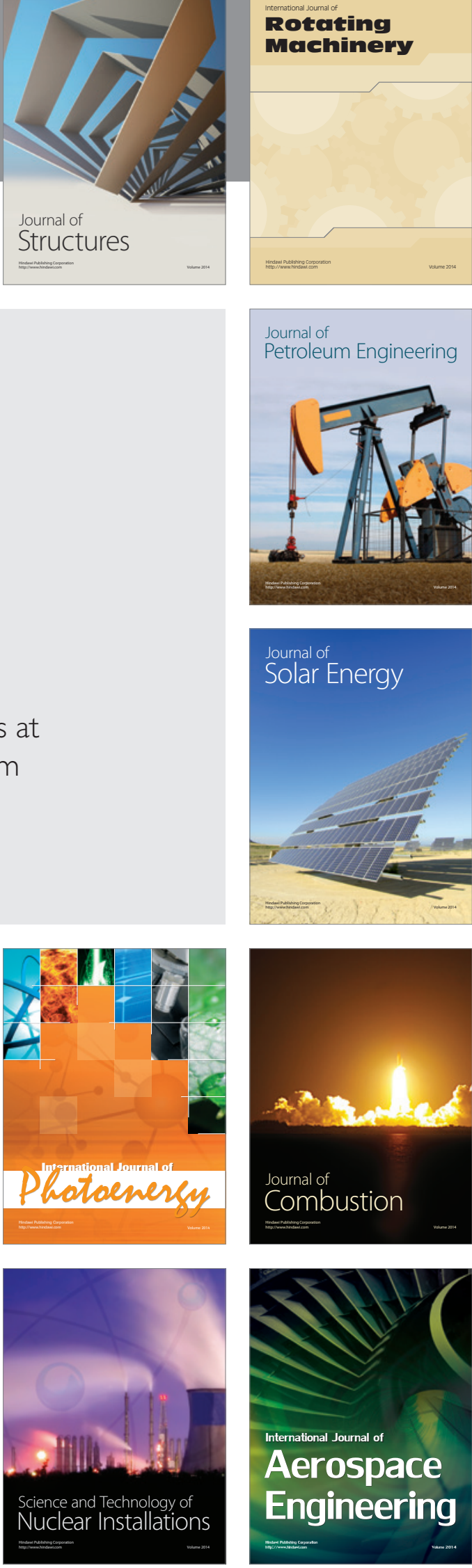